\title{
THE INCIDENCE OF DEEP VEIN THROMBOSIS IN ORTHOPAEDIC PATIENTS UNDERGOING MAJOR LOWER LIMB SURGERIES WITH OR WITHOUT THROMBOPROPHYLAXIS: A COMPARATIVE STUDY
}

\author{
Nagam Kirthi Chandra1, Sai Pavan Kumar Murari²
}

${ }_{1}^{1}$ Assistant Professor, Department of Orthopaedics, Apollo Institute of Medical Sciences and Research, Hyderabad.

${ }^{2}$ Senior Resident, Department of Orthopaedics, Apollo Institute of Medical Sciences and Research, Hyderabad.

\begin{tabular}{l}
\hline ABSTRACT \\
BACKGROUND \\
There is paucity of data regarding the development of Deep Vein Thrombosis (DVT) without prophylaxis compared with \\
thromboprophylaxis in Indian population.
\end{tabular}

\section{OBJECTIVE}

To evaluate the requirement of thromboprophylaxis, complications of therapy, its advantages and disadvantages in patients undergoing major orthopedic surgeries of lower limb.

\section{METHOD}

This comparative study was conducted in 164 patients; preoperatively patients were screened, categorized into high risk and low risk groups. Randomly selected patients received prophylactic antithrombotic therapy (Category A), while others did not (Category B). Patients were closely monitored for DVT and pulmonary embolism. Colour Doppler was done for all on $5^{\text {th }}$ to $7^{\text {th }}$ postoperative day or till active ambulation.

\section{RESULT}

Mean age of the patients was 52 yrs. Patients in high risk group were 62 (37.8\%). Major surgeries included Dynamic Hip Screw for trochanteric and basic cervical fractures in 68 (41.4\%) patients and hemiarthroplasty with bipolar and Austin Moore prosthesis for fracture neck of femur in 36 (21.9\%). Median length of inpatient stay was 08 days with median time required for ambulation 07 days. Of 71 patients in Category-A, eight (11.2\%) were clinically symptomatic for DVT, of which only two (2.8\%) had positive Colour Doppler. Of 93 patients in Category-B, 40 (43\%) were symptomatic and seven (7.5\%) had positive colour Doppler.

Excessive blood loss was recorded in 14 patients in Category -B. There were three deaths in the high risk patients (02- Category-B).

\section{CONCLUSION}

Primary thromboprophylaxis with LMWH decreased post-surgical complications. In spite of increased blood loss, thromboprophylaxis is worth considering.

\section{KEYWORDS}

Colour Doppler, Deep Vein Thrombosis, LMWH, Primary Thromboprophylaxis, Pulmonary Embolism.

HOW TO CITE THIS ARTICLE: Chandra NK, Murari SPK. "The incidence of deep vein thrombosis in orthopaedic patients undergoing major lower limb surgeries with or without thromboprophylaxis: a comparative study." Journal of Evolution of Medical and Dental Sciences 2015; Vol. 4, Issue 105, December 31; Page: 17001-17004, DOI: 10.14260/jemds/2015/2570

\section{INTRODUCTION}

Deep Vein Thrombosis (DVT), a complication associated with major surgeries, especially with lower limb surgeries, can lead to fatal clinical conditions such as Pulmonary Embolism (PE). ${ }^{1}$ Incidence of DVT and is higher in United States of America. ${ }^{2}$ compared to Asia. ${ }^{3-6}$ Available data from Asia suggests that $41 \%$ of patients developed DVT post major joint surgeries without thromboprophylaxis. ${ }^{7}$

There is limited data on the incidence of DVT in India due to which incidence has been reported to be lower in our population. ${ }^{8}$

Financial or Other, Competing Interest: None.

Submission 22-12-2015, Peer Review 23-12-2015,

Acceptance 28-12-2015, Published 30-12-2015.

Corresponding Author:

Dr. N. Kirthi Chandra,

Assistant Professor,

Department of Orthopaedics,

Apollo Institute of Medical Sciences \& Research,

Hyderabad-500034.

E-mail: nkcr_24@yahoo.com

DOI:10.14260/jemds/2015/2570
Earlier, incidence of DVT in Indian patients was considered to be low. ${ }^{9-12}$ However, there is an increased reporting of DVT among orthopedic patients in India due to various reasons. ${ }^{13-14}$ Singh $\mathrm{R}$ et al. have reported $18.13 \%$ patients undergoing lower limb surgery developed DVT of which $24.24 \%$ were symptomatic. ${ }^{15}$ Gupta $\mathrm{N}$ et al. ${ }^{16}$ have observed that $17 \%$ of their patients developed DVT post lower limb surgery following trauma. Agarwala $\mathrm{S}$ et al.11 have found it to be $60 \%$ in patients without thromboprophylaxis.

Recommended thromboprophylaxis include mechanical (Compression stockings) and pharmacological interventions. Latter include low molecular weight heparin (LMWHenoxaparin rivaroxaban), unfractionised heparin, and oral anticoagulants (Warfarin, antiplatelet agents). Guidelines suggest thromboprophylaxis in hospitalized patients be initiated after assessing risks.

Thromboprophylaxis has shown to reduce the development of DVT and other complications in those undergoing surgery.

Duration of thromboprophylaxis varies with the different surgeries; in orthopedic surgeries, longer duration 
may be required after major orthopedic surgeries, especially those involving lower limbs, as DVT may develop even after several weeks post-surgery.

We observed that there is paucity of data among Indian population regarding the development of DVT without prophylaxis compared to with thromboprophylaxis. Hence, we conducted this comparative study in patients undergoing major orthopedic surgeries of the lower limb with and without DVT prophylaxis.

\section{MATERIALS AND METHODS}

This comparative study was conducted in 164 patients undergoing major orthopaedic lower limb surgery, in a teaching hospital in south India. We intended to evaluate the requirement of thromboprophylaxis, determine the duration and dosage of thromboprophylaxis, complications of therapy (If any), and its advantages and disadvantages.

Patients of both genders of $>40$ yrs. undergoing major lower limb surgeries were included in the study. Major surgery was defined as any procedure under spinal or general anesthesia that expected to take more than 30 minutes and required at least one week of stay in the hospital. Patients allergic to heparin, those on hormonal therapy, with h/o severe hemorrhage episodes in previous three months and known cases of bleeding diathesis were excluded.

Preoperatively included patients were assessed clinically and categorized into high risk (Obesity, diabetes, previous H/o DVT, paralytic patients) and low risk (Normal) group. Preoperative screening included surgical profile, laboratory investigations including hematology, biochemistry, 2D echo and colour Doppler for high risk cases.

All high risk group patients were evaluated for DVT by Colour Doppler preoperatively; therapeutic anticoagulation was started in positive cases till their inclusion in the low risk group; those who were found negative were included in the low risk group.

Haemoglobin estimation was done on the $1^{\text {st }}$ postoperative day. Patients were closely monitored for any signs of DVT and Pulmonary Embolism clinically during their stay in the hospital and at one week interval. Colour Doppler was done for all the patients on $5^{\text {th }}$ to $7^{\text {th }}$ Post-Operative Day (POD) or till the patients actively ambulant. Chest X-ray was done for the patients after one month of day of surgery.

Randomly selected patients were given prophylactic antithrombotic therapy (Category A), while others were without antithrombotic prophylaxis (Category B).

\section{ANTITHROMBOTIC PROPHYLAXIS}

Randomly selected patients received 2500 IU of Dalteparin Sodium (Fragmin) in prefilled syringes. Each patient received the injection by subcutaneous portal administered in the abdominal wall. Low risk group and high risk group with negative colour Doppler were given low molecular weight heparin (LMWH) from the day of admission. High risk group with positive Colour Doppler were started on therapeutic anticoagulants. In both the groups LMWH was stopped on the day of surgery and restarted on the first post-operative day.

\section{STATISTICAL ANALYSIS}

Data was captured on Microsoft Excel worksheet and analysed. Descriptive statistics, frequency tables, mean and percent were used to portray the results. Chi square test was used to find out $P$ value.

\section{RESULTS}

One hundred and sixty four patients meeting the selection criteria were enrolled in to the study with a male:female ratio of 103:61. Male patients accounted $62.8 \%$. Mean age of the patients was 52 yrs. and 95 (57.9\%) were above 65 years of age. Patients in high risk group with diabetics, obesity and hemiparesis were $62(37.8 \%)$ and those in low risk groups were $102(62.1 \%)$. Patients with body weight $<65 \mathrm{kgs}$ was 64.03\% (105/164) (Table 1).

Dynamic Hip Screw (DHS) was done for trochanteric and basic cervical fractures in $68(41.4 \%)$ patients. Hemiarthroplasty with bipolar and Austin Moore prosthesis was done for fracture neck of femur accounted for 36 (21.9\%) of cases. Cemented total hip replacement was done in 11 $(6.7 \%)$ of patients in old fracture neck of femur and in cases of secondary osteoarthritis of hip. Total knee replacement was done for $27(16.4 \%)$ patients and Dynamic Condylar Screw (DCS) in 22 (13.4\%) (Table 2). Median length of inpatient stay was 8 days (Interquarantile range).

Of 71 patients in Category-A, eight (11.2\%) were clinically symptomatic, of which only two $(2.8 \%)$ had positive Colour Doppler. These patients were treated with therapeutic dose of LMWH. Seventy one randomly selected patients received 2500 IU of Dalteparin Sodium (Fragmin) in prefilled syringes. Low risk group and high risk group with negative colour Doppler were given LMWH from the day of admission. High risk group with positive Colour Doppler were started on therapeutic anticoagulants. In both the groups LMWH was stopped on the day of surgery and restarted on the first POD up to $7^{\text {th }}$ post-operative day.

Of 93 patients in Category-B, 40 (43\%) of patients were symptomatic and seven $(7.5 \%)$ were seen with positive colour Doppler. The median time of ambulation period in these patients were 7 days ( 6 to 9 days).

\section{MORTALITY}

There were three deaths in our study occurred in the high risk patients; two in category B (2.15\%) and one in category A (1.4\%). There was no death in the low risk patients.

In category-A, a female patient, aged 62 yrs. died on the 7 th POD, due to pulmonary embolism, DHS fixation was done on the same side. Colour Doppler done on the $6^{\text {th }}$ POD was positive.

There were two deaths in category B. A male patient aged 75 years who underwent arthroplasty died due to pulmonary embolism; this patient was poorly ambulant, colour Doppler done on the 7 th POD was moderately positive. A female patient aged 68 years died suddenly due to myocardial infarction on $9^{\text {th }}$ POD. Both these patients were symptomatic on the $5^{\text {th }}$ and $6^{\text {th }}$ Post-operative day.

\section{BLEEDING}

Blood loss was calculated as difference between the preoperative hemoglobin and post-operative Haemoglobin. Excessive blood loss was recorded (>2gms) in 16 patients in Category A.

The median time of discontinuation of LMWH in these patients was 8 days. Excessive blood loss was recorded in 14 patients in Category -B (Table 3). 


\section{FOLLOWUP}

In category A, only $47.89 \%$ (34/71) patients returned for follow up for 4 weeks after surgery; of these 34 patients, 28 patients $(82.36 \%)$ were ambulatory and two $(5.88 \%)$ were wheel chair bound or poorly ambulant. Latter two patients did not show any sign of DVT clinically. Three did not come for further follow up. The Chest X-ray of all the patients was insignificant. There was death that occurred on the $7^{\text {th }}$ postoperative day. (Table 4).

In category B, only $61.2 \%$ (57/93) patients returned for follow up for 4 weeks after surgery; of these 57 patients, 45 patients (48.4\%) were ambulatory and 10 (10.7\%) were wheel chair bound or poorly ambulant. Latter 10 patients did not show any sign of DVT clinically. The Chest X-ray of all the patients was insignificant. There were two deaths that occurred on the $6^{\text {th }}$ and $9^{\text {th }}$ Post-Operative day.

\section{DISCUSSION}

Association of development of DVT after major surgeries especially after major orthopedic surgeries is well established, hence these patients are considered to be at higher risk. It has been estimated that approximately $3 \%$ of patients who undergo major orthopedic surgeries without thromboprophylaxis develop clinically overt VTEs. ${ }^{17}$ and asymptomatic DVTs are seen in $30-80 \%$ patients. ${ }^{7,18-19}$ This study was designed to compare the clinical outcome and complications amongst those patients with prophylaxis with LMWH and those without, as data available is limited.

In our study, there were more number of male patients (62.81\%); $57.93 \%$ were $>65$ years age, $64.02 \%$ were weighing $<65 \mathrm{kgs}$. Lee SY et al. ${ }^{20}$ have observed the incidence of DVT increases with age, higher incidence seen in patients $>50$ years; in our study $57.93 \%$ patients were $>65$ years and increased incidence was seen in females, unlike our study.

Diagnosis of DVT is complicated as many of them remain asymptomatic; available diagnostic tests apart from clinical diagnosis are fibrinogen-uptake test (Leg scan), Impedance plethysmography (IPG), Doppler ultrasonography, duplex ultrasound scanning and venography. We opted for ultrasonography as a diagnostic tool in all cases. Other tests were not considered due to cost factor.

Various guidelines. ${ }^{21-22}$ recommend the use of primary prophylaxis in adult patients undergoing orthopedic, other major surgeries and recommend the use of Unfractionated Heparin (UFH) or LMWH as the first choice. We used Dalteparin for routine prophylaxis which was effective and well tolerated. Results of this study recommend the use of routine thromboprophylaxis in all major orthopedic surgeries to reduce the mortality, morbidity. It should be noted that the first dose was given on the day of admission, stopped on the day of surgery and restarted on the first postoperative day.

We administered Dalteparin for eight post-operative days, which was usually the time the patient was actively ambulant

Adverse effects of thromboprophylaxis include slight increase in blood loss; intracerebral and intragastric bleeding in those with acid peptic disease. We observed slight increase in intraoperative blood loss, but not as significant compared to those without any prophylaxis.

Incidence of DVT in our study was $2.8 \%(02 / 71)$ in patients with DVT prophylaxis and 7.5\% (07/93) in those without DVT prophylaxis. N. Rajagopalan. ${ }^{23}$ recorded $7.8 \%$ incidence of DVT in patients thromboprophylaxis by
Dalteparin. V. Bagaria et al. ${ }^{24}$ recorded $6.12 \%$ incidence of DVT and $0.6 \%$ of Pulmonary Embolism in a prospective study without thromboprophylaxis. Sharma $\mathrm{H}$ et al. ${ }^{25}$ recorded $19.6 \%$ of DVT incidence without thromboprophylaxis in patients undergoing surgeries around the hip joint. Mavalankar AP et al. ${ }^{26}$ recorded $7.2 \%$ of DVT incidence in a prospective study.

In our study the mortality was $1.4 \%$ in patients on thromboprophylaxis as compared to $2.1 \%$ in those who were without thromboprophylaxis. The morbidity rates were $11.2 \%$ in those who received thromboprophylaxis as compared to $43 \%$ in those who did not receive any prophylaxis which was statistically significant $(\mathrm{p}=0.00)$.

Our study had few limitations. We opted for ultrasonography, though not optimal for detection of thrombi in asymptomatic patients, especially distal and small proximal thrombi as a diagnostic tool in all cases. Although there was more number of deaths in those who did not receive any prophylaxis, the exact cause of death was not arrived at.

Colour Doppler was the only test which was used to detect any signs of DVT. Other screening methods such as 125 I-fibrinogen leg scanning which is more effective in detecting DVT was not used.

Since continuation of thromboprophylaxis with LMWH, included economic considerations, the cost effectiveness of thromboprophylaxis has to been taken into account. LMWH was discontinued in few patients where it was thought that they were actively ambulant. Minor thromboembolic episodes were unnoticed.

We conclude that, thromboprophylaxis is necessary, and LMWH are preferred for those who undergo major lower limb orthopedic surgeries. Thromboprophylaxis should be started early, at the time of hospital admission and continued till the patient is ambulant which takes approximately 7-9 days; if ambulation is delayed, it should be continued till patient is ambulated.

To minimize intra-operative bleeding, it is advised to stop LMWHs on the day of surgery. Thromboprophylaxis was associated with fewer complication compared to those who were without. Increased intraoperative haemorrhage was noted in those who received thromboprophylaxis.

\section{CONCLUSION}

Primary thromboprophylaxis with LMWH has proved advantageous as it decreased the complications such as DVT, Pulmonary embolism and Sudden death which may occur following major orthopaedic surgeries.

In spite of increased blood loss with thromboprophylaxis it is worth considering in terms of associated decreased morbidity and mortality rates of it.

\section{REFERENCES}

1. Monreal M, Ruíz J, Olazabal A, et al. Deep venous thrombosis and the risk of pulmonary embolism. A systematic study. Chest 1992; 102:677-81 [PubMed].

2. [No authors listed]. Prevention of venous thrombosis and pulmonary embolism. NIH Consensus Development. JAMA. 1986; 256:744-9. [PubMed].

3. Chumnijarakij T, Pashyachinda V. Post-operative thrombosis in Thai women. Lancet 1975; 1:1357-8.

4. Cunningham IG, Young NK. The incidence of deep vein thrombosis in Malaysia. Br J Surg 1974; 61:482-3. 
5. Lawrence JR, Xabregas A, Gray L, et al. Seasonal variation in the incidence of deep vein thrombosis. Br J Surg 1977; 64:777-80.

6. Nandi PL, Li WS, Leung R, et al. Deep vein thrombosis and pulmonary embolism in the Chinese population. Hong Kong Med J 1998; 4:305-10.

7. Piovella F, Wang CJ, Lu H, Lee K, Lee LH, Lee WC, et al.; AIDA investigators. Deep-vein thrombosis rates after major orthopedic surgery in Asia. An epidemiological study based on postoperative screening with centrally adjudicated bilateral venography. J Thromb Haemost 2005; 3:2664-70.

8. Parakh R, Kakkar VV, Kakkar AK. Venous Thromboembolism (VTE) Core Study Group. Management of venous thromboembolism. J Assoc Physicians India. 2007; 55:49-70.

9. Tinkler LF. Absence of Pulmonary Embolism in Asians? British Medical Journal. 1964; 1:502.

10. Stulberg BN, Insall JN, Williams GW, et al. Deep vein thrombosis following total knee replacement: An analysis of six hundred and thirty eight arthroplasties. Jl of Bone and joint surgery.1984; 86:194-201.

11. Agarwala S, Bhagwat A, Modhe J, et al. Incidence of deep vein thrombosis in Indian patients. A prospective study in 104 patients. Indian J Orthop 2003;37:5

12. Mok CK, Hoaglund FT, Rogoff SM, Chow SP, Ma A, Yau AC. The incidence of deep vein thrombosis in Hong Kong Chinese after hip surgery for fracture of the proximal femur. Br J Surg 1979 Sep; 66(9):640-2.

13. Shah S, Bhalodia R, Patel K, et al. Prevalence of deep vein thrombosis with lower limb trauma patients. International Journal of Biomedical and Advance Research. 2015; 6:1519.

14. Lee AD, Stephen E, Agarwal S, et al. Venous thromboembolism in India. Eur J Vasc Endovasc Surg. 2009 Apr; 37:482-5

15. Singh R, Muzzafar K, Bhat KA, et al. Incidence of deep vein thrombosis in patients undergoing a major lower limb surgery in tertiary care centre of North India. International Journal of Advanced Research. 2015; 3:1073-77.

16. Gupta N, Bhargava R. Incidence of post-operative venous thromboembolism using compression ultrasonography following trauma to spine and long bones of lower extremity. Open Journal of Orthopedics. 2013; 3:97-101.

17. White RH, Romano PS, Zhou H. A population-based comparison of the 3-month incidence of thromboembolism after major elective/urgent surgeries. Thromb Haemost. 2001; 86:22-55. (Abstract).

18. Prevention of venous thrombosis and pulmonary embolism. NIH Consensus Development. JAMA. 1986; 256:744-749. [PubMed].

19. Clagett GP, Anderson FA Jr, Heit J, et al. Prevention of venous thromboembolism. Chest. 1995; 108(4 Suppl):312S-334S. [PubMed].

20. Lee SY, Ro du H, Chung CY, Lee KM, Kwon SS, Sung KH, et al. Incidence of deep vein thrombosis after major lower limb orthopedic surgery: analysis of a nationwide claim registry. Yonsei Med J. 2015;56:139-45.
21. VTE prophylaxis guidance. British Orthopedic Association London. Updated 2015. Available from http://www.boa.ac.uk/publications/vte-prophylaxisguidance/. Accessed on 15/Dec/2015.

22. Venous thromboembolism: reducing the risk for patients in hospital. NICE Guidelines (CG92). Available from https://www.nice.org.uk/guidance/cg92. Accessed on 15/Dec/2015.

23. Rajagopalan N. Thromboprophylaxis by dalteparin sodium in elective major orthopaedic surgery-A multicentric Indian study. Indian J Orthop 2003;37:4.

24. Bagaria V, Modi N, Panghate A, et al. Incidence and risk factors for development of venous thromboembolism in Indian patients undergoing major orthopaedic surgery: results of a prospective study. Postgraduate Medical Journal. 2006; 82:136-139.

25. Sharma H, Maini L, Agrawal N, Upadhyay A, Vishwanath J, Dhaon BK. Incidence of deep vein thrombosis in patients with fractures around hip joint: a prospective study. Indian J Orthop 2002;36:5.

26. Mavalankar AP, Majmundar D, Rani S. Routine chemoprophylaxis for deep venous thrombosis in Indian patients: Is it really justified? Indian Journal of Orthopaedics. 2007;41:188-193.

\begin{tabular}{|c|c|c|}
\hline $\begin{array}{c}\text { Demographic } \\
\text { Characteristics }\end{array}$ & Category A & Category B \\
\hline Gender & & \\
\hline Male & 48 & 55 \\
\hline Female & 23 & 38 \\
\hline Age (Years) & 30 & 39 \\
\hline $40-65$ & 41 & 54 \\
\hline$>65$ & & \\
\hline Weight (Kgs) & 45 & 60 \\
\hline$<65$ & 26 & 33 \\
\hline$>65$ & 31 & 31 \\
\hline High Risk & 40 & 62 \\
\hline Low Risk & \multicolumn{2}{|c|}{} \\
\hline Table 1: Demographic characteristics of patients \\
\hline \multicolumn{2}{|l}{}
\end{tabular}

\begin{tabular}{|c|c|c|}
\hline Surgery & Category A & $\begin{array}{l}\text { Category } \\
\text { B }\end{array}$ \\
\hline Dynamic Hip Screw & 37 & 31 \\
\hline Hemiarthroplasty & 21 & 15 \\
\hline Total hip replacement & 02 & 09 \\
\hline Total knee replacement & 05 & 22 \\
\hline Dynamic Condylar Screw & 06 & 16 \\
\hline Total & 71 & 93 \\
\hline \multicolumn{3}{|c|}{$\begin{array}{l}\text { Table 2: Surgical procedure performed } \\
\text { on study patients }\end{array}$} \\
\hline
\end{tabular}

\begin{tabular}{|c|c|c|c|c|}
\hline \multirow{2}{*}{$\begin{array}{c}\text { Blood loss } \\
\text { (gms) }\end{array}$} & \multicolumn{2}{|c|}{ Category A } & \multicolumn{2}{c|}{ Category B } \\
\cline { 2 - 5 } & $\begin{array}{c}\text { HIGH } \\
\text { Risk }\end{array}$ & $\begin{array}{c}\text { Low } \\
\text { Risk }\end{array}$ & $\begin{array}{c}\text { High } \\
\text { Risk }\end{array}$ & $\begin{array}{c}\text { Low } \\
\text { Risk }\end{array}$ \\
\hline$<1$ & 1 & 5 & 4 & 14 \\
\hline $1-2$ & 21 & 28 & 20 & 41 \\
\hline$>2$ & 6 & 10 & 5 & 9 \\
\hline Total & \multicolumn{3}{|c|}{$\mathbf{7 1}$} & 93 \\
\hline \multicolumn{3}{|c}{ Table 3: Intraoperative Blood Loss } \\
\hline
\end{tabular}

